\section{B.B.C. Services on Very High Frequencies}

For some time past it has been the policy of the British Broadcasting Corporation to inaugurate sound broadcasting services in Britain in the veryhigh-frequency band of 88-95 Mc./s. (see Nature, $173,248 ; 1954)$. In its second report the Television Advisory Committee (1952) recommended the adoption of frequency modulation for such veryhigh-frequency broadcasting and stated that the B.B.C. was ready to start the construction of the necessary stations for the Home Service. In July last year the Postmaster-General announced that the B.B.C. could proceed with the first stage of its plan, and he approved the installation of the first nine stations, which, it is estimated, will eventually provide a three-programme sound broadcasting service to about 75 per cent of the population in Britain. The purpose of very-high-frequency transmissions is to reinforce the existing medium-wave and long-wave services, reception of which is becoming difficult for many listeners because of the increasing interference from foreign stations and from electrical appliances of various kinds.

The first of the new transmitting stations, using frequency modulation, was brought into service at Wrotham, Kent, some twenty-three miles south-east of London, on May 2. The three programmes are on the following frequencies: the Light Programme, 89.1 Mc./s.; Third Programme, $91.3 \mathrm{Mc} / \mathrm{s}$.; and the Home Service, $93.5 \mathrm{Mc} / \mathrm{s}$. The effective radiated power is $120 \mathrm{~kW}$. in each case, and the transmissions are horizontally polarized. The station will serve the London area and the south-east of England within a range of about fifty miles. The B.B.C. built Wrotham in 1950 as an experimental station with two transmitters to enable the problems of highpower very-high-frequency transmissions and their reception to be studied. The third transmitter, which has more recently been built, carries the Home Service and differs from the two already installed in that it is built as two separate units for operation in parallel, with each unit capable of maintaining the service at reduced power in the event of a fault on the other. For the first few weeks, only one of these transmitter units will be in operation, and the Home Service transmissions will not be at full power ; the effect of this is not likely to be noticeable except at extreme range.

\section{William Ramsay Centenary Appeal}

IN 1952, a hundred years after the birth of Sir William Ramsay, an appeal for $£ 100,000$ was launched with the following two objects : to construct additional laboratory accommodation in Ramsay's old Department of Chemistry at University College, London; and to make an addition to the general capital fund of the existing Ramsay Memorial Fellowship Trust in order to restore the number of British Ramsay Fellows to the original figure from which it had fallen owing to the decrease in the value of money. The appeal has been successful, and the Trustees have now issued a report (pp. 23 ; from University College, London, 1955). The report gives a list, with amounts, of all the subscribers: "The Centenary Appeal was directed chiefly to industry and industry has responded nobly". The division of the money is as follows: to University College, $£ 75,000$; to the Ramsay Memorial Fellowship Trust, $£ 19,500$; to the Glasgow Fellowship (for which a separate subsidiary appeal was made), $£ 4,200$. The new building for the Chemistry Department of
University College was completed in August last year, and it enables the Department to take on about forty more honours students and about twenty-five more research workers. Whereas the Fellowship Trust has in recent years only been able to support one Fellow at a time, the increase in its funds will allow it to support two or, on occasion, three Fellows at a time. The report of the Trustees gives a brief résumé of the history of the Trust since it was first raised in 1916 after Ramsay's death, and lists the names of the 152 Ramsay Fellows to date, with brief notes on their careers.

\section{Libraries in Colleges of Further Education in Britain}

A REPORT on "Libraries in Colleges of Further Education", prepared as Publication No. 20 by the Regional Advisory Committee for Librarianship of the London and Home Counties Regional Advisory Council for Higher Technological Education (pp. $12 ; 1954 ; 1 s$.$) , details recommended standards of$ accommodation, books and equipment for such libraries. It is contemplated that the libraries concerned should not only provide books and accommodation for both staff and students but should also encourage the use of printed matter among students and act as a clearing-house for both external and internal information. Not less than three rooms should be provided : a reading room and library of at least $2,700 \mathrm{sq}$. ft., and smaller rooms for a workroom and storage, respectively. The position of the library is also important: it should be quiet but central. Professional advice is essential on equipment, which should follow standard patterns as far as possible. Sound-absorbing material is recommended for floor-covering, and liberal provision made for technical equipment, including a microfilm reader. Adequate lighting should be maintained at shelf- and table-level, and provision for hanging up the outdoor clothes of readers is essential. Generally, a minimum initial stock of ten thousand items is essential for an institutional library to function efficiently, but the value of any library administered by a qualified librarian is enhanced enormously by the provision of bibliographical aids. The capital cost of such a stock at 1954 prices would be not less than $£ 10,000$, and the stock would require replacement over each decade so that $\mathfrak{f 1 , 0 0 0}$ a year must be allowed for this purpose, apart from improvements and current purchases, estimated at $£ 500$ a year or more. Work at advanced- and university-levels demands greater provision, particularly for periodicals, which represent an increasing charge. Binding and provision of photographic copies of articles not available in the library are further charges to be allowed for in the budget, and it is recommended that the librarian should attend meetings of boards of studies and teachers' conferences and be kept informed of any projected developments in the curriculum.

\section{British Information Services Overseas}

IN opening an adjournment debate in the House of Commons on British Information Services on April 19, Dr. Horace King, who has recently returned from a lecture tour, on behalf of the Foreign Office, in the United States, Canada and Iceland, paid a warm tribute to the work already being done. More British people are needed abroad if Britain is to make her full contribution to world peace. Particularly he urged the extension of the work of British Information Services in Canada, and he fully 